\title{
Acoustic Emission Technique, an Overview as a Characterization Tool in Materials Science
}

\author{
C. R. Ríos-Soberanis \\ Centro de Investigación Científica de Yucatán \\ Calle 43 No. 130 C.P. 97200 \\ Mérida, Yucatán, Mexico \\ rolando@cicy.mx
}

\begin{abstract}
In order to predict the mechanical behavior of a composite during its service life, it is important to evaluate its mechanical response under different types of external stresses by studying the initiation and development of cracks and the effects induced by damage and degradation. The onset of damage is related to the structural integrity of the component and its fatigue life. For this, among other reasons, non-destructive techniques such as acoustic emission (AE) have been widely used nowadays for composite materials characterization. This method has demonstrated excellent results on detecting and identifying initiations sites, cracking propagation and fracture mechanisms of polymer matrix composite and ceramic materials. This paper focuses on commenting the importance of the acoustic emission technique as a unique tool for characterizing mechanical parameters in response to external stresses and degradation processes by reviewing previous investigations carried out by the author as participant. Acoustic emission was employed to monitor the micro-failure mechanisms in composites in relation to the stress level in real-time during the tests carried out. Some results obtained from different analysis are discussed to support the significance of using $A E$, technique that will be increasingly employed in the composite materials field due to its several alternatives for understanding the mechanical behavior; therefore, the objective of this manuscript is to involve the benefits and advantages of $A E$ in the characterization of materials.
\end{abstract}

Keywords: Polymer matrix, mechanical properties, cermets, acoustic emission.

\section{RESUMEN}

Para lograr una predicción de las propiedades mecánicas de un material compuesto durante su vida en servicio, es importante evaluar su respuesta mecánica bajo diversos tipos de esfuerzos externos estudiando la iniciación y desarrollo de grietas así como los efectos inducidos por el daño y la degradación. El inicio del daño está relacionado con la integridad estructural del componente y su vida en fatiga. Por esta razón, entre otras, técnicas no destructivas tales como la emisión acústica (EA) han sido ampliamente empleadas en la caracterización de materiales. Este método ha demostrado excelentes resultados en la detección y determinación de los sitios de iniciación, propagación de grietas y mecanismos de fractura en compuestos de matriz polimérica y cerámica. Este artículo se enfoca en remarcar la importancia de la técnica EA como una herramienta única para la caracterización de los parámetros mecánicos en respuesta a esfuerzos externos y el proceso de degradación. La emisión acústica fue empleada para monitorear los mecanismos de micro-falla en compositos en relación al nivel de esfuerzo en tiempo real durante la prueba llevada a cabo. Resultados obtenidos de diferentes análisis son discutidos para apoyar la importancia de utilizar EA., técnica que será empleada en mayor demanda en el campo de los materiales compuestos debido a sus diversas alternativas para comprender el comportamiento mecánico; por lo tanto, el objetivo de este escrito es involucrar los beneficios y ventajas de la técnica EA en la caracterización de materiales.

\section{Introduction}

The understanding about damage generation from initiation and propagation until total fracture is of great importance for the materials design, development and application. Microstructural failure mechanisms are strongly dependant on several factors in any composite material such as the nature of the components, reinforcement/matrix interface, volume fractions, reinforcement geometry etc. Different types of damage mechanisms have been identified for fiber-reinforced composites such 
as matrix damage (matrix micro-cracking, coalescence of micro-cracks, matrix/matrix friction), interfacial debonding (fiber/matrix, bundle/matrix), fiber/matrix and fiber/fiber friction and fiber and bundle breaks [1-3]. The identification and evaluation of damage or fracture stages of polymer composites are extremely complex due to a composite material exhibiting heterogeneous nature, lacking of uniformity in composition owing to its components and, therefore, the assignment may be controversial. On the other hand, Ceramicmatrix composites have gained some interest in the scientific and the industrial world owing to their increased toughness and damage tolerance compared with monolithic ceramics. Multiple matrix cracking, interface debonding and fiber pull-out have been identified as the main mechanisms that contribute to their enhanced toughness ${ }^{[4,5]}$. Thereupon, the mechanism of fracture from crack initiation and propagation is also an important parameter to acknowledge. When a failure mechanism is activated, a burst of energy is released as elastic waves that propagate from the failure source through the medium. Acoustic emission is a suitable technique for the detection of a wide range of micro-structural failures in different materials ${ }^{[0-10]}$. The $\mathrm{AE}$ measurement is based on the detection of surface movements caused by stress waves of the fracture processes on a microscopic scale. The interpretation of the signals and, hence, the evaluation of the damage stages is a major problem of the $A E$ method. The major difficulty in establishing a relationship between a specific failure mode and its acoustic signature is the concurrent observation of different modes. Monitoring of acoustic emission (AE) signals generated by the rapid release of energy from localized sources within a material has developed rapidly over the last two decades as a technique for nondestructive evaluation and as a tool for materials research ${ }^{[11,12]}$. There is some experience in the qualitative interpreting of correlations between conventional $\mathrm{AE}$ features like amplitude distribution, counts, duration, etc., and the true damage mechanisms as well as friction or noise. However, absolute values of all these features are changed by the wave travelling through the test specimen in consequence of materials and geometric effects like attenuation, dispersion, reflection, etc. Therefore, conventional
$A E$ features are often not enough to make a distinction between several types of micro-failure mechanisms, consequently signal identification must be supported by additional characterization methods ${ }^{[9]}$. Nevertheless, this technique has demonstrated its wide versatility in evaluating mechanical behavior in different kind of materials in "real time".

\section{Acoustic emission technique}

The $A E$ technique is based on the detection of acoustic waves generated by the process of a rapid propagation of a microflaw or another kind of mechanical energy source [13, 14]. Piezoelectric sensors perceive the emitted signal from the damage notation site by the surface dynamic movement and convert it in an electrical response. Generally, a frequency between $50 \mathrm{kHz}-1 \mathrm{MHz}$ is used since lower frequencies are related to external noise. Undoubtedly, the acoustic signal response is very versatile due to the wide variety of parameters which can be identified. Figure 1 exhibits the obtained data through the $A E$ technique where it is possible to correlate the registered signals to the failure mechanisms of a given material identifying damage development stages such as microcracks, delamination, interface failure, matrix cracking, fiber breakage, etc. The most important setting for the reliable acquisition of acoustic emission information is the threshold value since only signals that cross the pre-defined threshold level are registered and evaluated. By this means, acoustic signals emitted by the material under stress (tension, compression, bending, etc) are isolated from external noise due to equipment vibrations ${ }^{[14]}$.

Two types of signals are detected by the $A E$ technique; they can be either burst or continuous (Figure 2). A burst signal is simply identified since the beginning and the end can be easily recognized. It is also correlated to any source mechanisms of short duration such as crack initiation, fiber/matrix friction, fiber breakage, particle impact, etc. On the other hand, a continuous signal is endless although the amplitude and frequency content can change over time. These signals are generally correlated to external noise. 


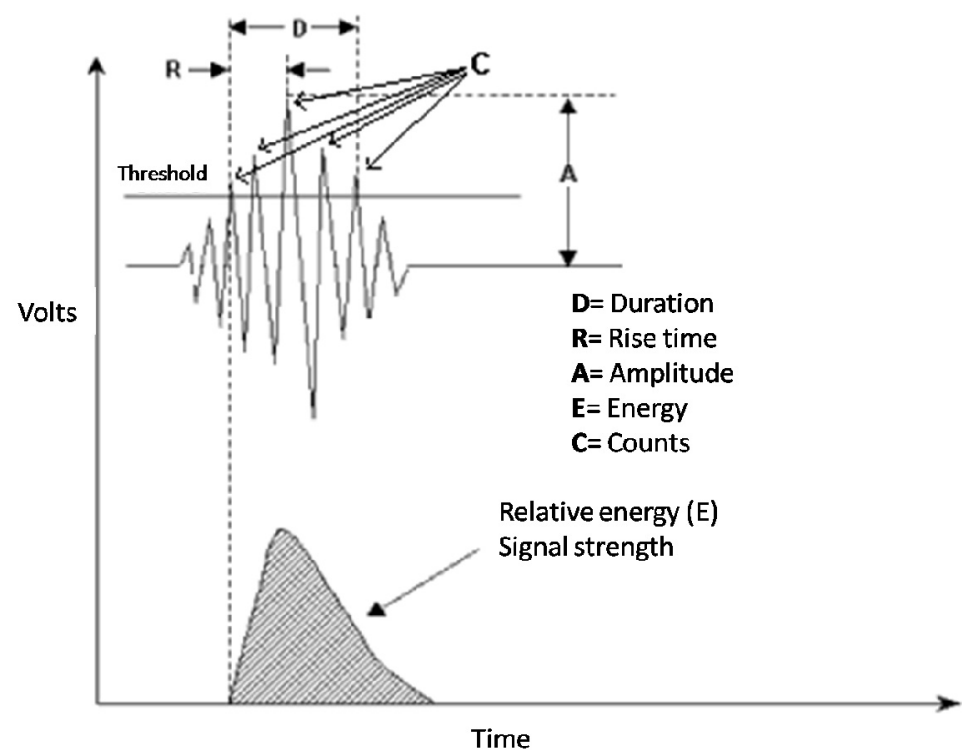

Figure 1. Typical parameters of acoustic emission signals.

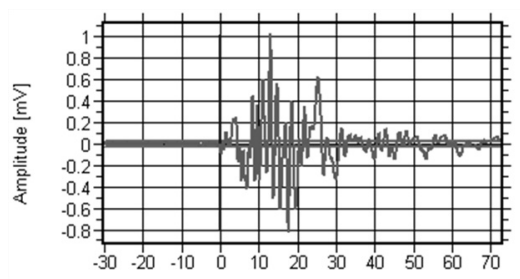

(a)

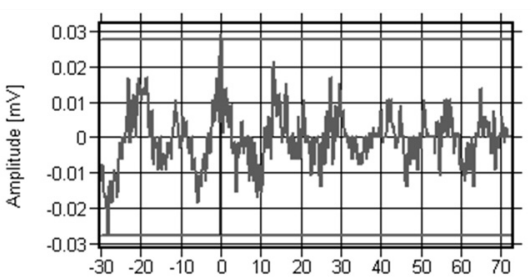

(b)

Figure 2. Typical emission signals: (a) burst and (b) continuous.

In order to highlight the benefits of the acoustic emission technique as a unique tool in materials science characterization, three researching studies will be discussed.

2.1 Identification of damage initiation sites in textile-reinforced composites

A Milano weft-knitted fabric produced from E-glass yarns of $2 \times 68$ tex was the textile to be investigated by making composite materials using the wet impregnation technique with one layer of the reinforced textile. In addition, a number of panels with 5 layers of knitted fabric were also fabricated. These panels were manufactured by using the resin transfer moulding (RTM) method. Samples for mechanical testing in tension were cut according to the load axis direction and the knitted architecture at $0^{\circ}, 45^{\circ}$, and $90^{\circ}$. The matrix used for the one layer lamina panel was an epoxy resin and the coupons enable the initiation of damage to be observed directly as they are completely transparent. The overall fiber volume fraction of the laminates was $29 \%$. RTM materials were produced 
by placing 5 layers of the Milano weft-knitted fabric in a mold, which was injected with Derakane vinyl ester resin resulting in a high-fiber volume fraction of $47 \%$. An Instron machine was used for mechanical testing and crack development. The output of the strain gauge, Vishay boxes and the load cell was connected to a data logging system. The crosshead speed for all tests was kept constant at 0.5 $\mathrm{mm} / \mathrm{min}$. Photographs were taken before loading at intervals during the test and after failure in order to observe crack accumulation and quantify crack densities. During testing, acoustic emission was monitored as a guide to damage initiation. There were three acoustic transducers in the system used in these experiments. One was the signal transducer, which was placed in the centre of the gauge length of the coupon. The other two were placed near the ends of the coupon (Figure 3). These guard transducers filter out unwanted noise from the grips of the tensile testing machine.
A computerized acoustic emission system (AECL $2100 . \mathrm{M}$ ) has been used to monitor stress waves as a result of generation and growth of defects. $A E$ signals were detected by the sensor and sent to a pre-amplifier and amplified by $60 \mathrm{db}$ gain. Most of the external noise (spurious signals) had peak amplitude levels below $40 \mathrm{db}^{[9]}$. Preliminary analysis was performed to establish the best threshold value, which was found to be $0.6 \mathrm{~V}$, allowing the sensor to collect only those events whose signal exceeded this value. The processing unit was set to count the number of acoustic events in $0.1 \mathrm{~s}$ intervals (values were plotted as acoustic emission count rates). The $\mathrm{AE}$ output from the processing unit was connected to the data logger for simultaneous recording with the other monitored parameters (i.e. load, strains). As shown in Figure 4, matrix cracking damage and the pattern of cracking are intimately related to the fabric architecture and the fabric orientation with respect to the loading direction.

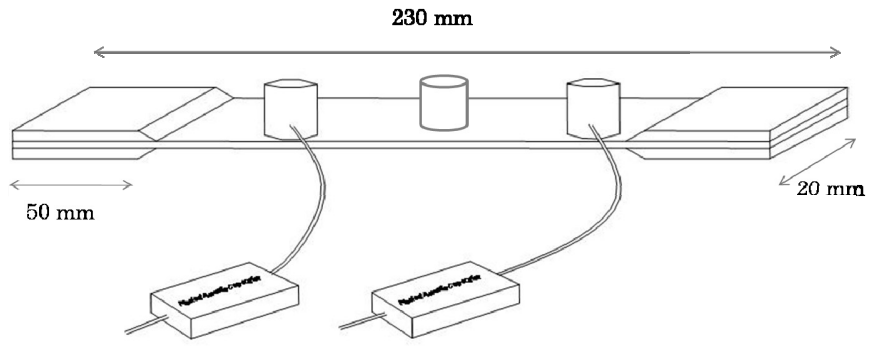

Figure 3. AE sensors and materials dimensions for tension test.

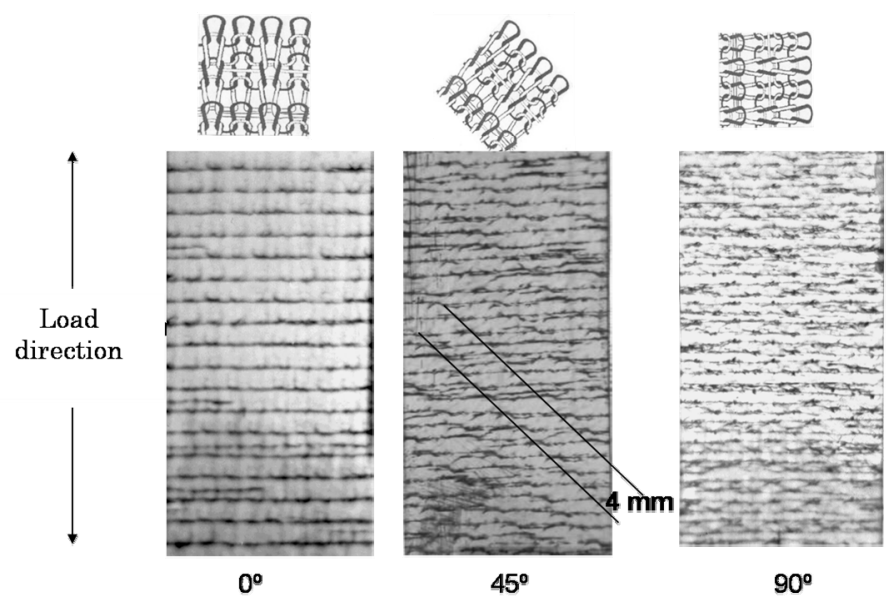

Figure 4. Damage development in the composite at $0^{\circ}, 45^{\circ}$, and $90^{\circ}$ 
Despite the textile orientation, cracks seem to follow the fabric geometry. As it can be observed in Figure 5, the typical stress-strain curve for a sample with the knitted fabric wale direction parallel to applied stress $\left(0^{\circ}\right)$ displayed linearity until about $1.0 \%$ strain when the first major cracks appeared in the material and were registered as discontinuities in the curve. The acoustic emission signal is initially recorded just before these main cracks appear (about $0.85 \%$ strain) indicating that some microdamage in the composite is happening. However this damage is not visually noted in the sample. This mechanical behavior was observed in all the samples at any angle tested: the registration of $A E$ signals previous to significant cracks indicating damage initiation. Taking $A E$ data in account, samples were tensile loaded until the first signals were detected by sensors. The coupon was unloaded and pieces were cut and a detailed polish process was carried out on them. After that, the pieces were analyzed by SEM in order to identify the initiation of such microdamage. Results by electronic microscopy demonstrated that the first damage occurs as microdebonding between the loop cross-over points in the knitted fabric structure (Figure 6).

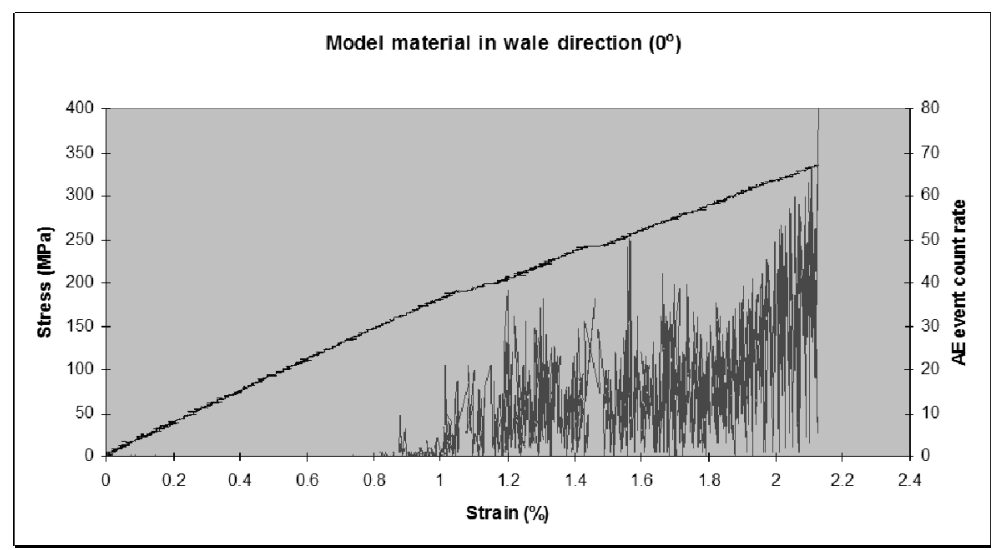

Figure 5. Stress-strain curve for a sample material at $0^{\circ}$ (wale direction).

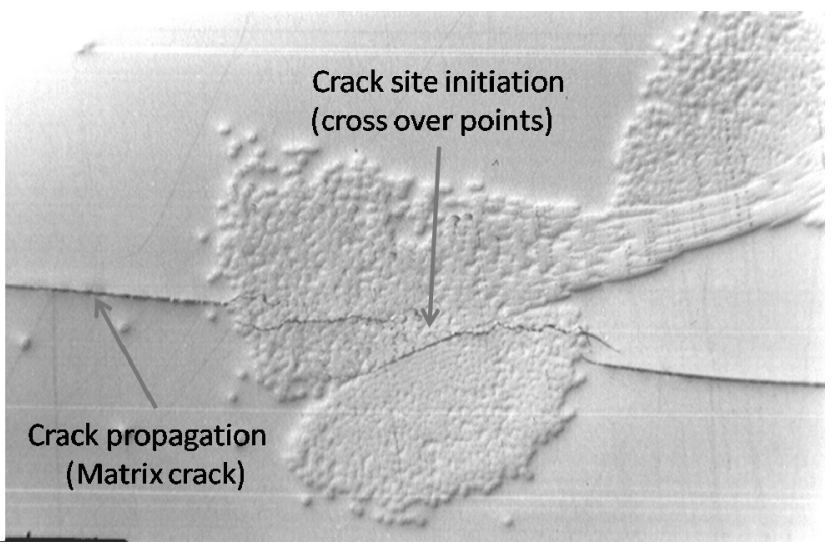

Figure 6. Damage initiation points and propagation of mayor cracks. 
On the other hand, the composite manufactured using 5 layers by the resin transfer moulding (RTM) process was also tested in order to compare the damage behavior of a structural material. Typical stress-strain curves for samples with the wale direction $\left(0^{\circ}\right)$ of the fabric are shown in Figure 7. In this case, Derekane vinyl ester was used as matrix. In general, the stress-strain curves in all samples at all textile orientations appear nonlinear from even very small strains. In these opaque RTM materials, it was impossible to determine the onset of cracking visually and the acoustic emission (AE) technique was used to monitor damage. Acoustic emission (AE) activity is shown together with the stress-strain curves. $A E$ activity begins at quite low strains (approximately $0.2 \%$ to $0.4 \%$ ). From strains of about $0.2 \%$ to $1 \%$, the $A E$ event count rises slowly, but a dramatic increase is observed from about $1.0 \%$ strain. All coupons had strain gauges parallel and perpendicular to the loading direction so that the transverse strains were also measured.
Figure 8 displays the damage propagation in RTM samples at $0^{\circ}, 45^{\circ}$, and $90^{\circ}$. It was clearly observed that even though the matrix was not transparent, the cracks appeared firstly in the surface as white bands allowing determining that flaws were following again the reinforced textile architecture just as observed before with the one layer composite.

Although it was difficult to visualize any clear relationship between damage generation and the textile reinforcement architecture, as observed with the one layer composite, microanalyses were carried on utilizing the $A E$ signal information. Pieces were cut at strain values where microdamage was supposed to initiate. It was found that the flaws initiation sites were the cross-over (Figure 9) points just as observed before. The first evidence of damage appears at cross-over points, and then cracks coalesce to run along the material by matrix cracking until fracture.

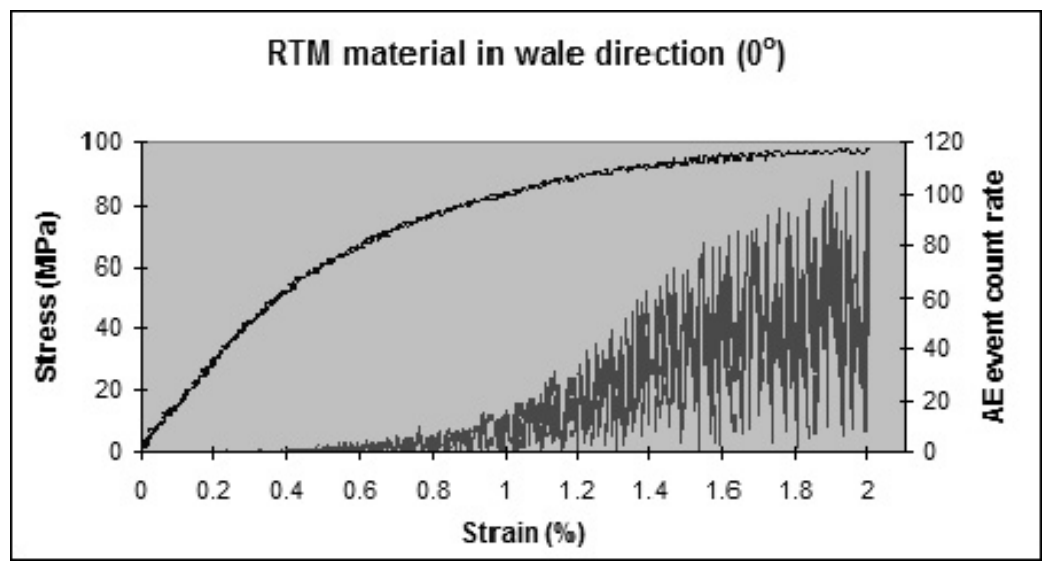

Figure 7. Stress-strain curve for RTM material tested at $0^{\circ}$. 


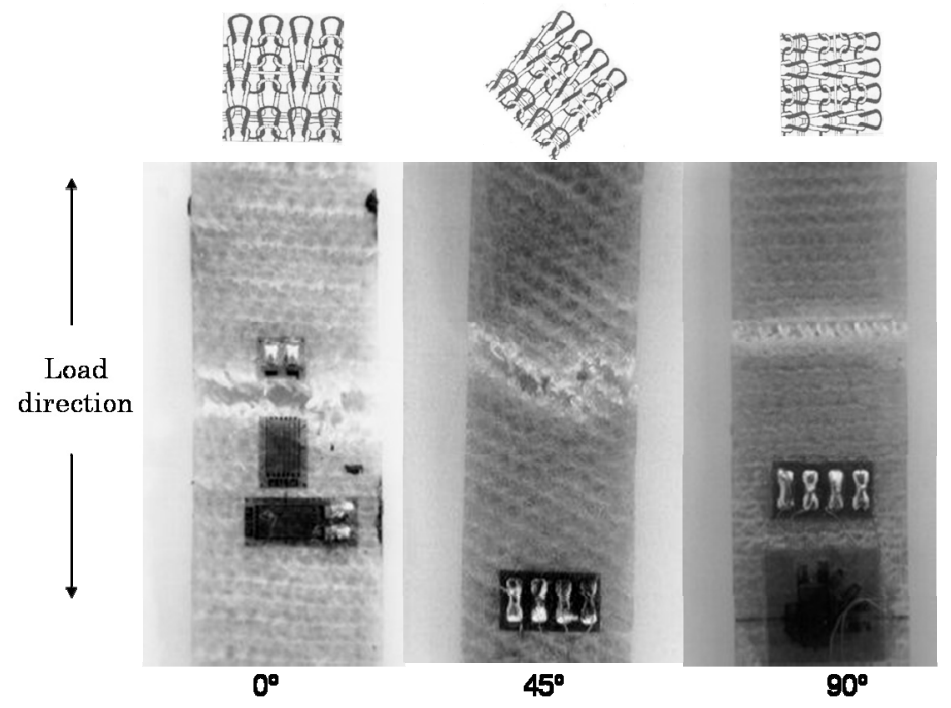

Figure 8. Damage development in the RTM compositie at $0^{\circ}, 450 a n d ~ 90^{\circ}$.
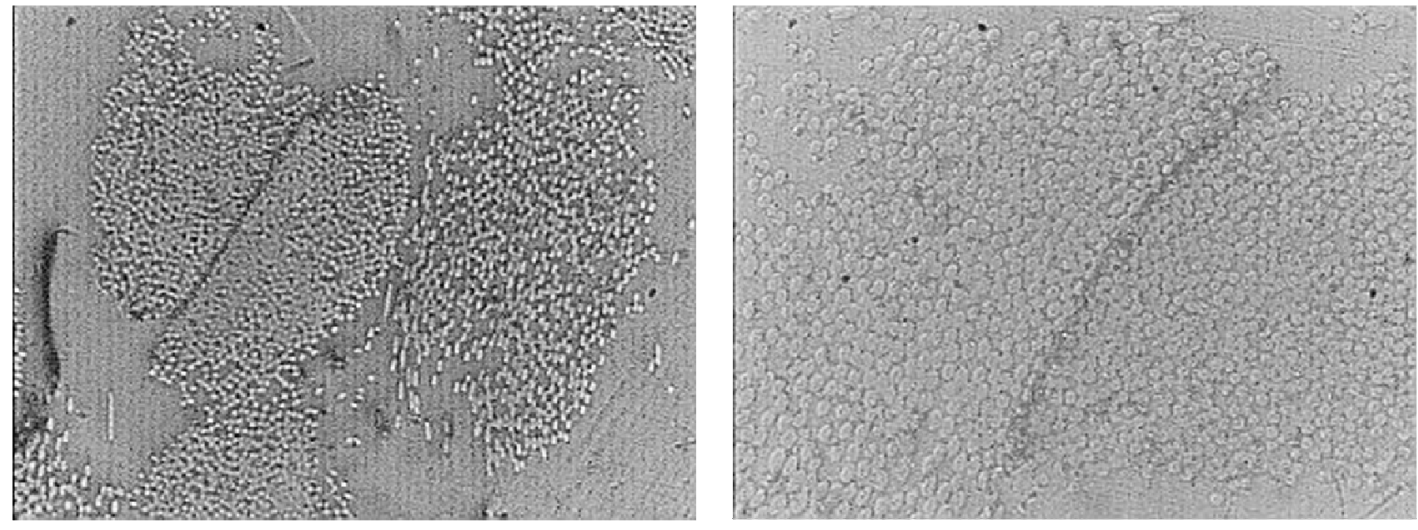

Figure 9. Damage development in the RTM compositie at $0^{\circ}, 450 a n d 90^{\circ}$. 
2.2 Determination of polymer matrix degradation by effect of humidity using acoustic emission

Fiber-reinforced composites are significantly affected by water absorption by weakening the fiber/matrix interface that, consequently, reduces its mechanical properties. humidity absorption in epoxy resins is a common problem of great importance. exposition of epoxy polymeric matrix in a humid environment can generate absorption of about 1 to $7 \%$ in weight into the polymer generating a decrease in its physical properties ${ }^{[15-}$ 17]. therefore, it is important to analyze the response of a resin system to degradation caused by humidity. this particular research was carried out by using an epoxy resin based on di-glycidyl ether of bisphenol a (dgba). the acoustic emission technique was used in order to monitor the matrix degradation. samples were obtained from resin laminates and placed in glass containers to $25 \%$, $55 \%$, and $95 \%$ of relative humidity in order to measure initially the percentage of absorbed humidity. humidity effect on the epoxy matrix was evaluated by studying the velocity of the acoustic wave in the medium. velocity of wave propagation was determined by taking into acount the delayed time $(\delta t)$ of signals produced when the sample failed registered in sensors 1 and 2 . this velocity was calculated for each sample having different relative humidity. figure 10 shows the dimensions and characteristics of the coupons including the position of both sensors and the notch.

Figure 11 shows the tendency followed by the velocity of acoustic signal when the resin has been exposed to prolonged times of $95 \%$ relative humidity. It is clear that epoxy matrix suffers certain degree of plasticization due to water absorption. At $2 \%$ humidity, the elastic wave propagation decreases approximately $22.7 \%$ this is because signal velocity depends significantly on the medium in which the energy is released. In a highly rigid material, displacement of the signal is rapid and intense in comparison with a material that exhibits a decrement in its stiffness properties, where the velocity is slower and less intense. In epoxy resin, after being submitted to high humiditycontrolled conditions, elastic modulus properties change from a rigid material behavior to a less rigid material originated by plasticization. Due to this phenomenon, the velocity of the acoustic signal is reduced by molecular attenuation.

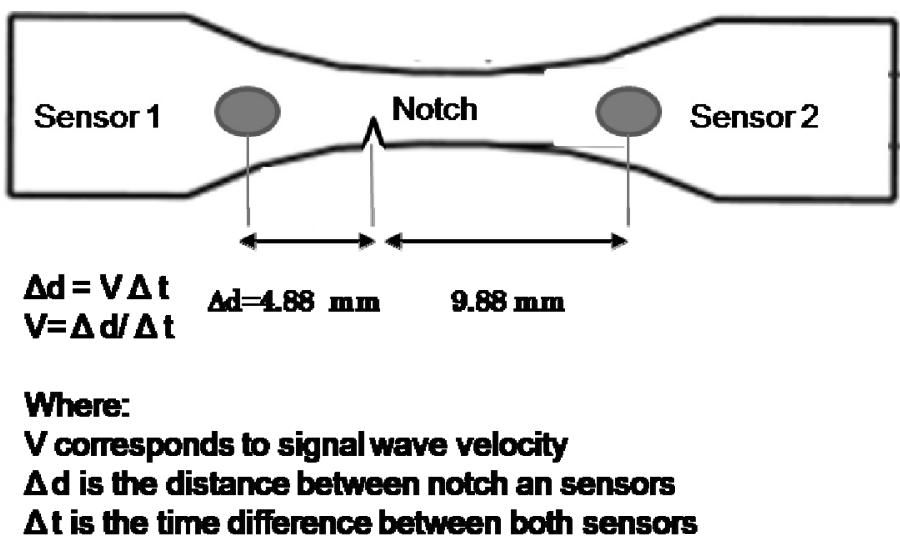

Figure 10. Sensors attached to matrix sample for AE measurement. 


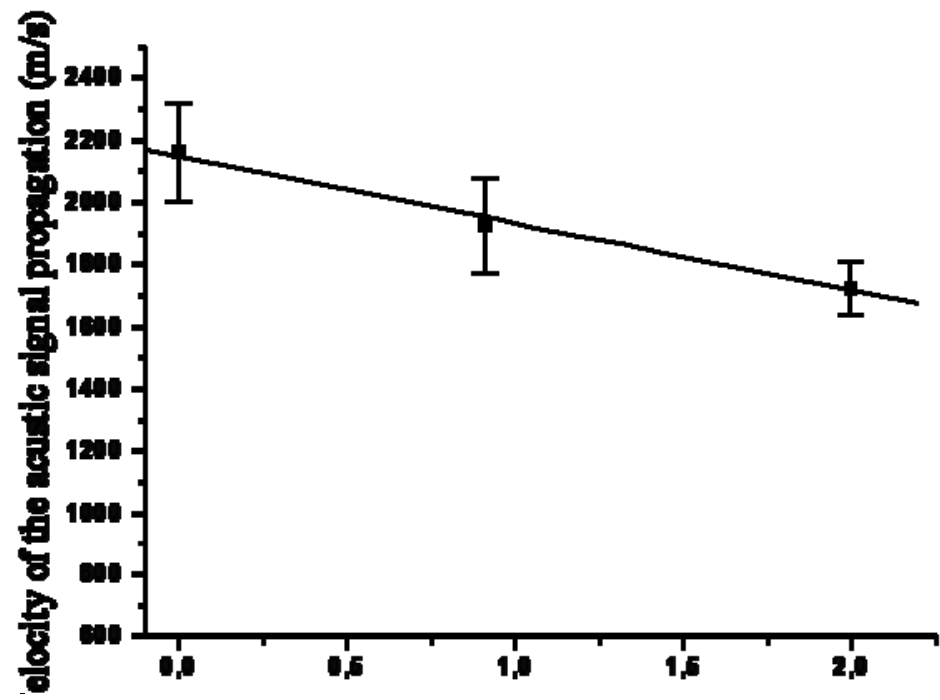

Figure 11 . Wave velocity attenuation produced by humidity absorption.

\subsection{Analysis of the failure mechanisms of cermets}

Acoustic emission can be used in different types of materials such as composites based on ceramic matrix filled with metallic particulates known as cermets ${ }^{[19-21]}$. Previous investigations have used the $A E$ signal parameters such as amplitude, events and energy to correlate them to different stages of mechanisms of fracture ${ }^{[22-23]}$. In this work, the failure mechanisms from crack initiation and propagation until fracture for $\mathrm{Ti}(\mathrm{C}, \mathrm{N})$-based cermets commonly used for extrusion dies, cutting tools, etc., was studied by the 4-point bending test. The edges of a tensile surface were chamfered, and both tensile and chamfered surfaces were polished to mirror finish to allow microscopic analysis. The acoustic emission technique was used to monitor the fracture behavior in real time. An schematic diagram of the 4-point flexural test system is shown in Figure12.

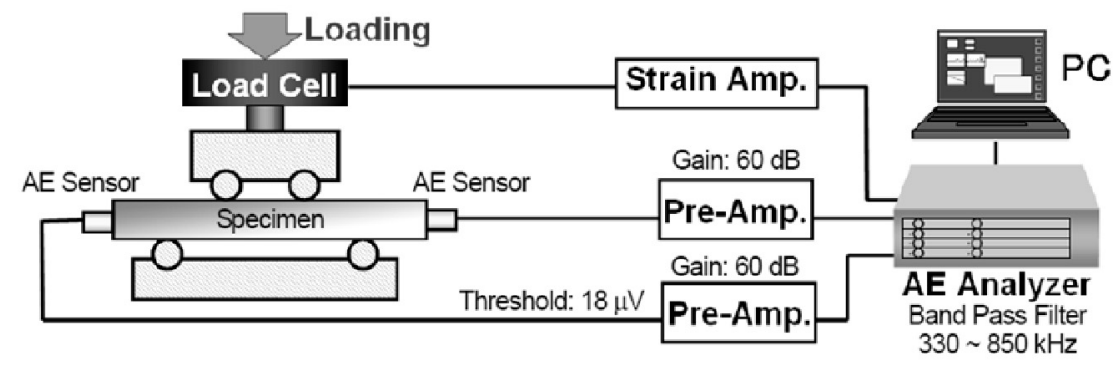

Figure 12. Diagram of the bending test and AE monitoring. 
The tests were conducted with the third-point loading $(L / 3)$, in this way, the loading points are each positioned one third of the support span length from the respective support, and hence are also one third of the support span length from each other. A loading rate of $0.1 \mathrm{~mm} / \mathrm{min}$ was used. $\mathrm{AE}$ sensors were place at the edges of the cermet rods as shown in Figure 13

Under the direct inspection of AE signals, different stages in the failure mechanisms were identified. Figure 14 displays the stress vs. time curve where it is possible to correlate with the $A E$ information. In this graphic, a rapid increase in cumulative $A E$ energy prior to the final fracture was observed, which could be related to the maincrack formation as the origin of final fracture. Different stages were identified by acoustic emission during the bending test. At low strain values, the AE signal is almost undetected during the elastic region, after approximately $190 \mathrm{~s}$ a major crack is recorded increasing the amplitude and the energy of the signals detected. When the stress is incremented, a constant augmentation in energy and amplitude is also observed (crack propagation) just prior to the rod fracture.

The failure mechanisms in cermets identified by AE signals can be summarized as follows: 1) At low strains, an elastic behavior is observed by both the carbide grains and binder phase, then, the binder starts to deform plastically. 2) When the stress is higher, microdamage appears separating the grains, after that, a main crack occurs emitting high energy and amplitude signals. 3) This significant crack propagates along the sample originating carbide/carbide and carbide/binder interphases damage and, finally, 4) the main crack propagates unstably until total catastrophic fracture.

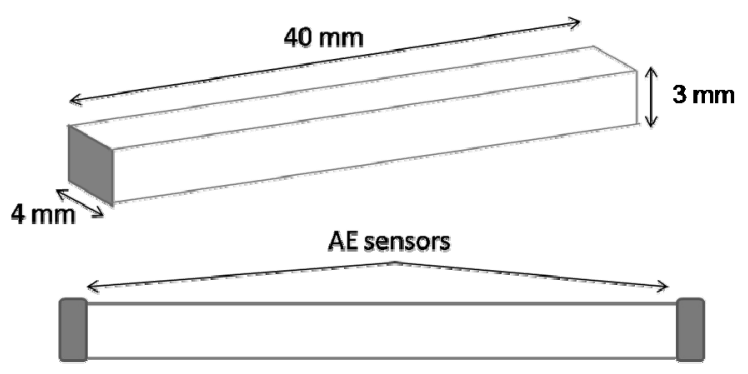

Figure 13. Dimensions of Cermet rods.

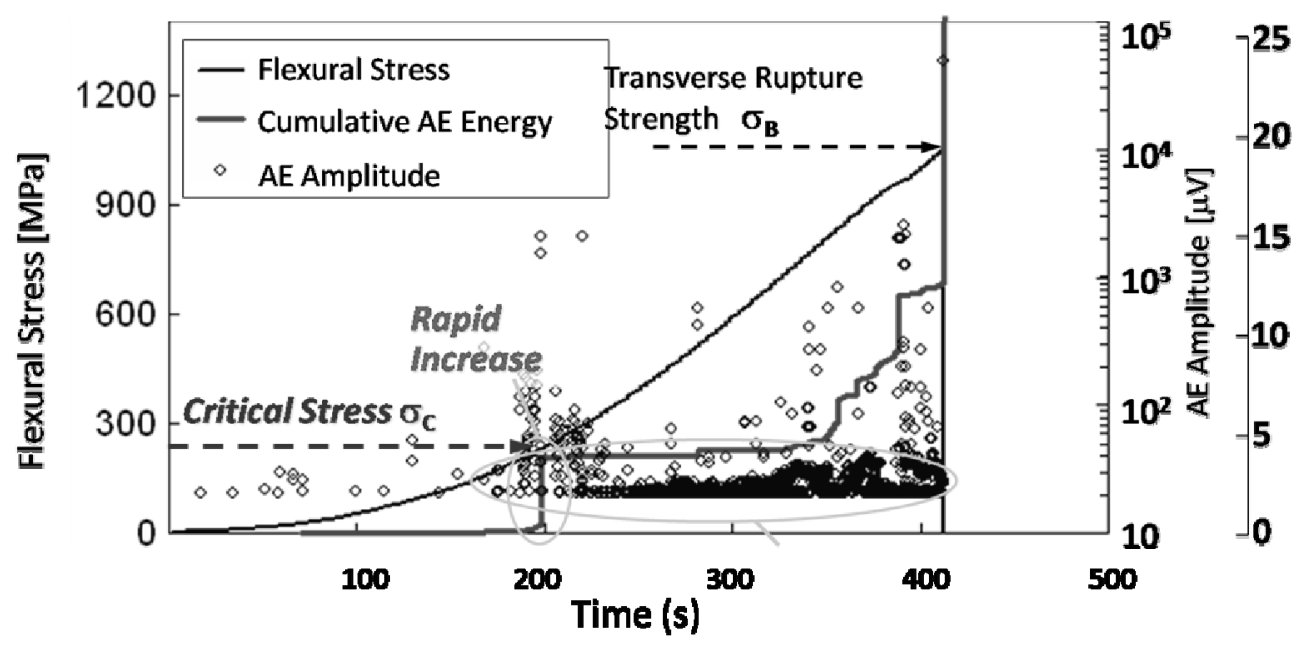

Figure 14. Stress vs. time vs. AE signals in bending test. 


\section{Conclusions}

Acoustic emission is an excellent tool for characterizing micromechanical behavior in materials science. As it was demonstrated in this review, it is possible to conclude that

a) A microdamage mechanism depends greatly on the nature of the components of the composite material so its response to external stresses will be displayed completely differently. Hence, it is necessary to use as many techniques available such as acoustic emission for this kind of studies.

b) Each stage exhibited different acoustic signals such as amplitude and energy depending on the type of damage generated, i.e. fiber/matrix interphase crack, matrix cracking, fiber breakage, degradation due to plasticity, etc. All of them can be detected and identified by the acoustic emission technique.

c) For textile reinforced composites, the damage generation from crack initiation and propagation can be related to the effect of the architecture/geometry of the textile. Loading direction in relation with the orientation of the textile is also important and has a direct consequence on the progression of damage in the material.

d) Acoustic emission can be used to measure de velocity of the elastic waves on the material, therefore, variations such as attenuation and dissipation can be related to materials degradation.

e) In cermets, the $\mathrm{AE}$ technique is an important technique for detecting changes in the properties due to damage evolution. Mechanisms of fracture can be evaluated and identified. Microscopy must be used as well to support the data obtained by $A E$ signals.

The use of $\mathrm{AE}$ will become more prevalent because it can provide unique insights into damage processes. The problems of $\mathrm{AE}-$ including noise reduction, reliability, and difficulty in solving the inverse problems of wave propagation in source-function and waveform analysesrepresent areas of future endeavor in AE science and technology. There is also a great need for work to develop AE theories for new applications.

\section{References}

[1] Giordano M, Calabro A, Esposito C, D'Amore A and Nicolais L, An Acoustic-Emission Characterization of the Failure Modes in Polymer-Composite Materials, Composites Science and Technology, Vol 58, 1998, pp. 1923-1928.

[2] Bohse J, Acoustic Emission Characteristics of MicroFailure Processes in Polymer Blends and Composites, Composites Science and Technology, Vol 60, 2000, pp. 1213-1226.

[3] Lieu YK, Shih WK and Jang BZ, Controlled Energy Dissipation in Fibrous Composites. II: Microscopic Failure Mechanisms, Polymer Composites, Vol 12, 1991, pp. 57-65.

[4] Bolognini S, Mari D, Viatte T and Benoit W, Fracture Toughness of Coated TiCN-WC-Co Cermets with Graded Composition. International Journal of Refracttory Metals and Hard Materials, Vol 19, No.4, 2001, pp. 285-292.

[5] Yan Q, Huang Z, Wang GY and Jiang D, The Effect of Microstructure on Toughness of Ni/Al2O3 Composites Prepared by Spark Plasma Sintering, Journal of Alloys and Compounds, Vol 461, 2008, pp. 436-439.

[6] Surgeon M, Vanswijgenhoven E, Wevers $M$ and Van Oer Biest O, Acoustic Emission During Tensile Testing of Sic-Fibre-Reinforced BMAS Glass-Ceramic Composites, Composites Part A, Vol 28, 1997, pp. 473-480.

[7] De Rosa IM, Santulli C and Sarasini F, Acoustic Emission for Monitoring the Mechanical Behavior of Natural Fibre Composites: A Literature Review, Composites: Part A, Vol 40, 2009, pp. 1456-1469.

[8] Zhuang $X$ and Yan $X$, Investigation of Damage Mechanisms in Self-Reinforced Polyethylene Composites by Acoustic Emission, Composites Science and Technology, Vol 66, 2006, pp. 444-449.

[9] Ramakrishna S, and Hull D, Tensile Behaviour of Knitied Carbon-Fibre-Fabric/Epoxy Laminates-Part 1: Experimental, Journal of Composites Science and Technology, Vol 50, 1994, pp. 237-247.

[10] Leong $\mathrm{KH}, \mathrm{S}$. Ramakrishna and Hamada $\mathrm{H}$, The Potential of Knitting for Engineering Composites, 5th Japan SAMPE Symposium. 1997, Tokyo, Japan.

[11] Sodomka L, Application of Acoustical Emission as a New Effective Diagnostic Tool in the Textile Fields, European Working Group Acoustic Emission, (EWGAE 26th). 2004, pp. 783-790, Berlin, Germany, September. 
[12] Hamsad, M.A. A Review: Acoustic Emission, a Tool for Composite-Materials Studies, Experimental Mechanics, 1985, pp. 7-13.

[13] Andreikiv, O. E., Skal's'kyi, V. R. and Serhienko, O. M. Acoustic-Emission Criteria for Rapid Analysis of Internal Defects in Composite Materials. Materials Science, Vol. 37, No. 1, 2001, pp.106-117.

[14] De Rosa, I.M., Santulli, C. and Sarasini, F. Acoustic emission for monitoring the mechanical behavior of natural fibre composites: A literature review. Composites: Part A, 40, 2009, pp.1456-1469.

[15] Soles, C.L., Chang, F.T., Gidley, D.W. and Yee, A.F. Contributions of the Nanovoid Structure to the Kinetics of Moisture Transport in Epoxy Resins. Journal of Polymer Science: Part B: Polymer Physics, Vol 38, 2000, pp.776791.

[16] Andreopoulos, A.G. and Tarantili, P.A. Water Sorption Characteristics of Epoxy Resin-UHMPE Fibers Composites. Journal of Applied Polymer Sciense, Vol. 70, 1998, pp.747-755,

[17] Soles, C.L., Chang, F.T., Bolan, B.A., Hristov, H.A., Gidley, D.W. and Yee, A.F. Contributions of the Nanovoid Structure to the Moisture Absorption Properties of Epoxy Resins, Journal of Polymer Science: Part B: Polymer Physics, Vol 36, 1998, pp.3035-3048.

[18] Surgeon, M., Vanswijgenhoven, E., Wevers, M. and Van Oer Biest, O. Acoustic Emission During Tensile Testing of Sic-fibre-Reinforced BMAS Glass-Ceramic Composites. Composites Part A 28A, 1997, pp.473-480.

[19] Wakayama, S. and Ishiwata, K. Fracture Analysis Based on Quantitative Evaluation of Microcracking in Ceramics Using AE Source Characterization, Journal of Solid Mechanics and Materials Engineering, Vol. 3, No. 2, 2009, pp.96-105.

[20] Bohlen, J., Dobron, P., Meza-Garcia, E., Chmelík, F., Lukáč, P., Letzig, D. and Kainer, K.U. The Effect of Grain Size on the Deformation Behaviour of Magnesium Alloys Investigated by the Acoustic Emission Technique. Advanced Engineering Materials, Volume 8, Issue 5, 2006, pp. 422-427.

[21] Ray, , A.K., Das, G., Mukhopadhyay, N.K., Bhattacharya, D.K., Dwarakadasa, E.S. and Parida, N. Studies on Indentation Fracture Toughness on Ceramic and Ceramic Composite Using Acoustic Emission Technique, Bulletin of Materials Science Volume 22, Number 1, 1999, pp.25-32.

[22] Yamada, K. and Wakayama, S., AE Monitoring of Microdamage During Flexural Fracture of Cermets,
EURO PM 2009, 2009, Copenhagen, Denmark, October.

[23] Oskouei, A. R., Ahmadi, M. and Hajikhani, M. Wavelet-Based Acoustic Emission Characterization of Damage Mechanism in Composite Materials Under Mode I Delamination at Different Interfaces. eXPRESS Polymer Letters Vol.3, No.12, 2009, pp.804-813

\section{Acknowledgements}

The Author would like to thank Dr. Shuichi Wakayama from Tokyo Metropolitan University for allowing research on the acoustic emission technique in his laboratory during the Author's sabbatical year. Acknowledgement is also due to student Kenjiro Yamada for sharing his knowledge and analysis techniques during the preparation of his thesis. 


\section{Author's Biography}

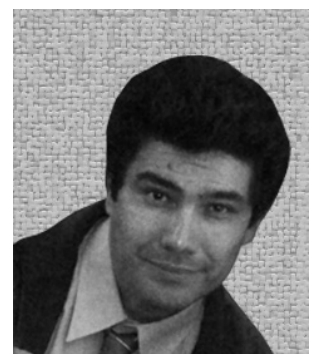

\section{Carlos Rolando RÍOS-SOBERANIS}

Dr. Ríos-Soberanis received his bachelor's degree in industrial chemistry from Universidad Autónoma de Yucatán, UADY, in 1992 . He earned his master's degree in advanced materials technology and the $\mathrm{PhD}$ degree from Surrey University (Guildford, England), in 1998 and 2002, respectively. Dr.RíosSoberanis spent a sabbatical year at Tokyo Metropolitan University, TMU, in Japan, from 2009 to 2010. His research is on degradation and damage generation analysis on polymer matrix composite materials, cermets and biopolymers using acoustic emission technique. Dr. Ríos-Soberanis has been a professor-researcher at Centro de Investigación Científica de Yucatán, CICY, since 2002. 